\title{
Martir dalam Perang Pattimura dan Implikasi pada Pembelajaran Sejarah
}

\author{
Leni Marpelina \\ lenimarpelina@gmail.com \\ Universitas Sebelas Maret
}

\begin{abstract}
This research purposed to analyze the role of Martha Christina Tiahahu in Pattimura war against the Dutch colonialism in Maluku and its implication to history learning nowadays. Martha Christina Tiahahu was one of the first female heroes who took arms against colonialism and slavery practiced by Dutch in Maluku. The discussion about Martha become urge nowadays because her patriotism and heroism values can be used as an idea to the young generation to fight against ignorance, confinement, and poverty as a citizen of the nation. The literature study was used as a method of the research by analyzing books and articles discussing Martha Christina Tiahahu. By discussing Martha and relate it to history learning, students are expected to build their collective memory and historical awareness about national heroes by understanding a historical event as a whole.
\end{abstract}

Keywords: Martha Christina Tiahahu, Pattimura War, History Learning

\begin{abstract}
Abstrak
Penelitian ini bertujuan untuk menganalisis peranan Martha Christina Tiahahu dalam perang Pattimura melawan kolonialisme penjajahan bangsa Belanda di Maluku dan bagaimana implikasinya dalam pembelajaran sejarah dewasa ini. Martha Christina Tiahahu adalah salah satu figur pejuang perempuan pertama yang ikut mengangkat senjata melawan penjajahan dan perbudakan yang di praktekan oleh bangsa Belanda di Maluku. Membahas Marhta dewasa ini menjadi penting karena nilai-nilai kepahlawanannya dapat dijadikan cita-cita bagi generasi muda untuk berperang melawan kebodohan, keterkungkungan, dan kemiskinan sebagai warga bangsa. Metode penelitian yang digunakan adalah studi literatur dengan menganalisis buku maupun artikel yang membahas mengenai Martha Christina Tiahahu. Dengan membahas mengenai Marta, maka diharapkan peserta didik dapat membangun memori kolektif tentang pahlawan nasional, serta memiliki rasa kesadaran sejarah yang tinggi sekaligus menambah wawasannya dalam memahami sebuah peristiwa sejarah secara utuh.
\end{abstract}

Kata Kunci : Martha Christina Tiahahu, Perang Pattimura, Pembelejaran Sejarah.

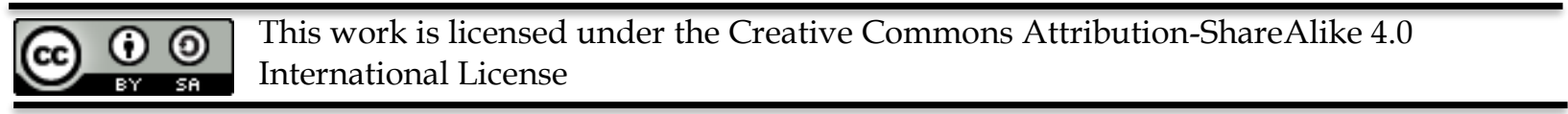




\section{Pendahuluan}

Martha Christina Tiahahu adalah seorang sosok pahlawan yang belum banyak diketahui oleh masyarakat Indonesia. Namun perlu diketahui, Martha Christina Tiahahu merupakan salah satu martir dalam perang Pattimura. Namanya hidup dalam memori kolektif masyarakat Maluku sebagai pahlawan Nasional. Sering disebut tatkala kita mempelajari Perang Pattimura, namun nama Martha seakan-akan hanya pelengkap dari kisah gerakan Pattimura melawan kolonialisme Belanda (Marpelina Leni, Akhmad A.M, 2019). Konteks ini merupakan hal yang dinamis dalam pengejawantahan telaah historis, bahkan refleksi historis dan refleksi kristis semestinya senada dalam kontek masa lalu demi mencari sumbangan literasi value. Martha Christina Tiahahu dengan segala warisan perjuanganya ketika ditafsir secara refleksi kritis mengilhami kita semua mengenai konsep penindasan yang di lakukan bangsa kolonial terhadap Indonesia. Darah revolusi mengalir untuk pembebasan kala itu, mungkin sekarang tafsir kemerdekaan sering muncul dalam teoritical heroism. Heroisme sebagai ekspresi aktualisasi diri dan keadaan sosial adalah kepentingan mendasar bagi psikologi humanistic (Franco et al., 2018).

Beberapa sumber historiografi tidak menyentuh nama Martha. Beberapa penulis tersebut antara lain Leirisa dalam buku yang berjudul "Indonesia Dalam Arus Sejarah jilid 4" tentang Pattimura Dari Saparua. Dalam tulisan tersebut nama Martha Christina Tiahahu Sama sekali tidak di cantumkan (Leirissa, 2013). Penulis lain misalnya “Buku sejarah Indonesia Modern" karya Ricklefs, ketika menjelaskan Perlawanan Pattimura sama sekali tidak menuliskan nama Martha (Ricklefs, 2008). Demikian halnya "Kamus Sejarah Indonesia" karangan Robert Cribb dan Audrey Kahin, nama Martha Christina Tiahahu tidak dimasukan dalam abjad (Cribb \& Kahin, 2012). Hal ini yang membuat nama pahlawan tersebut menjadi kurang dikenal oleh banyak orang. Salah satu penyebabnya adalah minimnya referensi yang membahas mengenai Martha Christina Tiahahu. Keterbatasan referensi tersebut menurut Humaidi diakibatkan oleh beberapa hal, pertama waktu perjuangan Martha Christina Tiahahu sangat singkat dalam waktu setahun. Kedua, narasi yang ditulis oleh bangsa Belanda bersifat sepihak. Ketiga, narasi yang muncul dari tradisi turun temurun yang sudah berbaur dongeng (Humaidi, 2015).

Faktor keterbatasan historiografi tersebut yang membuat narasi kepahlawanan Martha Christina Tiahahu tidak banyak ditulis dan dimasukan dalam referensi babon sejarah. Namun dari hasil penelusuran lebih dalam terbukti bahwa Martha Christina Tiahahu menyimpan sebuah konsistensi perjuangan yang luar biasa. Minimnya pembahasan mengenai ketokohan Martha Christina Tiahahu berimplikasi pada pembelajaran sejarah, dimana peserta didik menjadi kurang mengenali sosok pahlawan nasional. Proses internaslisai nilai-nilai kepahlawanan, semangat kejuangan, kebangsaan sangat penting untuk di ajarkan kepada peserta didik sebagai upaya menumbuhkan rasa patriotisme, di tengah-tengah tantangan globalisasi yang menyuguhkan tontonan figur kepahlawanan yang tidak mencerminkan nilai-nilai ketimuran (Wardani, 2016; Wiriaatmadja, 2002). Maka untuk itu, penting menggali, merekontruksi dan menghadirkan kembali nilai-nilai kepahlawanan tersebut yang diinternalisasikan dalam pembelajaran sejarah menjadi perlu.

Dalam konteks ini maka tujuan penulisan artikel ini adalah untuk menyampaikan sejarah pemberontakan Pattimura dan peran Martha Christina Tiahahu dalam menggerakkan rakyat 
menentang penjajah Belanda abad ke-18 di pulau perubahan Saparua Maluku tengah, dan bagaimana implikasi perjuangan Martha Kristina Tiahahu dalam pembelajaran sejarah. Sejarah bukan hanya tentang narativisme suatu peristiwa tetapi juga penjelasan tentang peristiwaperistiwa (Kartodirdjo, 1992). Berangkat dari pernyataan tersebut penelitian ini berupaya untuk menelusuri kembali bagaimana peranan seorang perempuan belia pada masanya yang ikut terlibat dalam upaya melawan penjajahan Belanda. Perempuan tersebut bernama Martha Christina Tiahahu.

\section{Metode Penelitian}

Metode yang digunakan dalam mengkaji permasalahan dalam penelitian ini adalah studi literatur dengan cara mempelajai berbagai sumber baik itu dari buku maupun artikel-artikel ilmiah dipublikasikan yang masih relevan dengan kajian penelitian (Zed, 2014). Melalui cara ini dapat dikaji dan dibahas berbagai persoalan yang berkaitan dengan masalah Martha Christina Tiahahu. Melaui ini juga dapat dianalisis peran Martha Christina Tiahahu dalam gerakan Pattimura melawan bangsa Belanda dan implikasinya terhadap pembelajaran sejarah.

\section{Hasil dan Pembahasan}

Martha Christina Tiahahu lahir pada tanggal 4 Januari 1800. Dilahirkan di daerah Nusa Laut yaitu tempat yang sangat terpencil di kepulauan Maluku, tepatnya di desa Abubu (Abobo). Dilahirkan dari pasangan suami isteri yang juga merupakan keturunan Kapitan atau panglima perang di Negeri Abubu yaitu Kapitan Paulus Tiahahu, yang juga membantu Thomas Matulessy selama perang Pattimura tahun 1817 melawan Belanda. Ayah dari kapitan Paulus Tiahahu adalah Tabiakan Tiahahu. Ibu dari Martha Christina Tiahahu bernama Petronela Warlau yang merupakan anak dari seorang kapitan di Negeri Titawai pulau Nusalaut. Sejak kecil Martha Christina Tiahahu telah di tinggalkan oleh ibunya sehingga ayahnya merangkap menjadi ayah sekaligus ibu untuk Martha. Ayahnya mengambil tanggungjawab sepenuhnya untuk mengasuh, mendidik dan membesarkan Martha Christina Tiahahu.

Jika ditinjau dari penampilan fisik, Martha menggambarkan karakteristik orang Melanesia: kulit agak gelap dan rambut bergelombang. Melanesia mengacu pada penduduk asli wilayah Melanesia. Indonesia selalu menjadi rumah besar bagi orang Melanesia, mereka tinggal di Papua, Papua Barat, Maluku, Maluku Selatan, Nusa Tenggara Timur, dan pulau-pulau kecil lainnya di sekitarnya. Mengikuti langkah ayahnya, Martha aktif dalam urusan militer sejak usia masih sangat belia. Di tengah pertempuran sengit, Martha selalu berteriak untuk membakar semangat pasukan yang sedang bertempur (Galinowicz, 2015). Sebagai puteri seorang kapitan, Martha Christina Tiahahu tentunya mendapatkan didikan secara disiplin oleh Ayahnya. Sejak kecil Martha Christina Tiahahu terkenal sebagai anak yang berkemauan keras dan pemberani. Sifatanya yang unik yang membuat dia dikenal oleh banyak orang. Pengaruh pendidikan ayahnyalah yang membangun karakter kuat pada diri Martha Christina Tiahahu yang selanjutnya menjadi modal dalam perjuangannya melawan Belanda. Kemanapun Paulus Tiahahu 
pergi, Martha selalu mendampingi, dan dari proses mendampingi inilah, Martha belajar arti perjuangan seorang pemimpin saat melakukan pembelaan kepada rakyat yang dipimpinnya.

Menurut J.A Pattikaihatu dalam bukunya yang berjudul "Biografi singkat dan tokoh pahlawanan nasional asal daerah Maluku" mengatakan bahwa Christina Tiahahu tercatat sebagai seorang pejuang yang unik yaitu langsung terlibat dalam medan pertempuran melawan tentara kolonial Belanda dalam perang Pattimura tahun 1817. Di kalangan para pejuang dan masyarakat sampai di kalangan musuh, ia di kenal sebagai gadis belia pemberani dan konsekuen terhadap cita-cita perjuangannya mengusir penjajahan dari wilayah Nusantara terutama di daerah Maluku (J.A, 1996). Tulisanya ini di perkuat oleh penulis sejarah daerah Maluku yaitu Jop Lasamahu dalam tulisanya yang berjudul "Putri Karang Di Laut Banda" mengatakan bahwa Martha Christina Tiahahu tidak pernah mundur setapak pun ia berjuang sampai titik darah penghabisan (J., 1984).

Antara rentang tahun 1600 hingga 1800, Maluku adalah daerah yang terus bergejolak melakukan perlawanan kepada pihak asing. Daerah Maluku yang kaya akan sumber rempah merupakan suatu anugerah dan sekaligus bencana bagi rakyatnya. Anugerah, karena rempahrempah bernilai ekonomis mahal dan pada akhirnya mampu meningkatkan kesejahteraan rakyatnya dan meningkatkan marwah kuasa para pemimpinnya. Adapun bencana, karena kekayaannya akan rempah mendorong beragam bangsa untuk datang dan menguasai kekayaan alamnya tersebut. Sejak 1512, Maluku terus menerus di datangi oleh bangsa asing yang mencari peluang untuk memonopoli dan mengambil keuntungan dari perdagangan dan penguasaan rempah-rempah. Adapun sejarah perlawanan terhadap bangsa asing, kiranya sudah hadir seiring dengan kedatangan bangsa asing itu sendiri. Pada awal kedatangan bangsa Portugis, terdapat ketokohan Sultan Khairun (1538-1575) dan Sultan Baabullah (1570-1583). Kapitan Hitu Kakiali (1634-1643), dan perlawanan Nuku antara tahun 1738-1805 juga berhasil menyingkirkan supremasi Belanda di wilayah Maluku.

Perlawanan Nuku, barangkali merupakan perlawanan yang menarik mengingat tidak hanya sekedar dilakukan perlawanan secara fisik. Perlawanan Nuku adalah perlawanan modern yang mampu memanfaatkan situasi geopolitik internasional, keberhasilan membangun jejaring relasi antara daerah-daerah terdekat serta keberanian dan kewibaaan dalam mengorganisir kekuatan. Kemudian awal abad XVII beberapa pulau di Maluku Tengah telah diubah dari daerah terbelakang menjadi produsen cengkeh bagi pasaran dunia. Namun penyelenggaran produksi cengkih itu dikendalikan oleh serikat dagang Belanda, yaitu VOC. Sejak Belanda berhasil mengambil alih Pulau Ambon dan pulau-pulau lainya dari Portugis tahun 1605, VOC memutuskan untuk menjadikan tempat tersebut sebagai tempat produksi cengkih terbesar di dunia. Sehingga perdaganganya di pasaran Eropa dapat di monopoli sepenuhnya. Kesewenangwenangan yang di lakukan oleh bangsa Belanda terhadap Maluku menjadi pemicu kemarahan rakyat. Salah satu orang yang paling terpengaruh terhadap suasana kemarahan yang melanda rakyat Maluku adalah Thomas Matulessy dan pada akhirnya rakyat Maluku mengangkat senjata dibawah pimpinan Thomas Matulessy. Perlawanan yang kemudian dilakukan oleh Thomas Matulessy dan para pejuang lain yang dikenal perang Pattimura pada 1817, adalah perlawanan yang banyak mencontoh dari gerakan perlawanan Nuku. Salah satu bentuk perlawanan yang 
dilakukan adalah dengan melakukan penyerangan Benteng Duurstede, yang merupakan duplikasi dari gaya serangan Bastille dalam revolusi Perancis.

Semangat Pattimura adalah semangat Maluku dalam melawan penjajahan Belanda. Alwin, mengatakan bahwa sejak kelahiranya Thomas Matulessy atau Kapitan Patttimura dianggap sebagai lambang kebangkitan rakyat Maluku (Alwi, 2005). Pada permulaan abad ke-19 semangat Pattimura berkobar membakar seluruh jiwa masyarakat Maluku. Kembalinya Belanda di Maluku maka saat itu juga aturan-aturan yang ditetapkan pada zaman Kompeni juga kembali di berlakukan oleh Belanda dalam hal ini perdagangan pasar bebas dilarang. Tekanan-tekanan Belanda juga juga telah nampak dalam tindakan yaitu pertama, memaksakan rakyat untuk menerima uang kertas jika rakyat menolak maka akan di cambuk menggunakan rotan. Kedua, mengahruskan rakyat membuka kebun cengkih dan pala untuk kepentingan Belanda, Ketiga, memaksa rakyat menebang kayu untuk keperluan bangunan pemerintah. Serta terakhir pemudapemuda di paksakan untuk masuk pelatihan militer yang akan di persiapkan untuk di tugaskan di jawa (Zachrias, 1984). Praktek kolonialisme yang semakin memburuk, melahirkan kondisi ketidakpuasan terhadap pemerintahan Belanda semakin menyebar di kalangan rakyat Maluku dan khususnya Saparua.

Pada awal bulan April tahun 1817 mereka mengadakan pertemuan rapat rahasia di hutan Liung yang bertujuan untuk mengangkat senjata melawan Belanda. Namun berita tersebut di bocorkan oleh mantan raja Hulaliu dan Pelau bernama Lattukomma Oma yang pada masa Inggris dipecat sebagai raja. Suasana semakin hari semakin memburuk sehingga Thomas Matulessy dan kawan-kawannya pada 3 Mei 1817 kemudian mengadakan rapat umum di Wailunyo dan memutuskan menyerang benteng Duurstede (Leirissa, 2013) untuk memulai gerakan perlawanan, yang terinspirasi serbuan benteng Bastille dalam revolusi Perancis. Menurut Kamajaya semangat perlawanan rakyat itu tersebar luas hingga seluruh penjuru kepulauan Maluku setelah mereka mengadakan pertemuan di Luang, Wailunyu dan hutan Seniri Saparua (Kamajaya, 1981). Pada tanggal 9 Mei 1817, untuk ke dua kalinya, Thomas Matulessy dan 6 orang temanya mengajak para pria untuk berkumpul di Wailunyo. Pertemuan tersebut bertujuan untuk memilih pemimpin perjuangan dan menurut sumber sejarah bahwa diantara yang hadir hanya Thomas Matulessy yang bersedia jadi Kapitan.

Tanggal 14 Mei 1817 di hutan Saniri pemuda dari segenap penjuru baik itu rakyat dari Honimoa (Saparua), Nusa Laut, maupun Haruku. mengadakan pertemuan rahasia kembali yang bertujuan untuk memilih pemimpin perjuangan rakyat Nusa Laut dan pengangkatan sumpah setia. Rapat tersebut di hadiri oleh Martha Christina Tiahahu dan ayahnya. Zachrias mengklaim bahwa Paulus Tiahahu dan putrinya menghadiri pertemuan ini, meskipun mereka datang terlambat (Zachrias, 1984).Pagi hari, sebelum Paulus Tiahahu berangkat menuju Saniri, anaknya Martha Christina datang menghadap ayahandanya. Martha membujuk dan merayu ayahnya agar ia diajak untuk berjuang bersama ayahandanya bergabung dengan pasukan perjuangan Pattimura. Raja Abubu tersebut, awalnya melarang anaknya ikut serta karena ia perempuan dan usianya masih tergolong muda. Namun, karena desakan dan kemauan keras Martha Christina, 
akhirnya Paulus Tiahahu mengizinkan anaknya bergabung untuk berjuang membantu Pattimura. Dalam pertemuan itu ketika Paulus diberi kesempatan untuk berbicara ia menggunakan kesempatan berbicara tersebut untuk mengajukan permintaan khusus kepada Pattimura (Zachrias, 1984):

“Thomas, raja-raja dan orang kaya, saya berkebaratan terhadap tindakan pemerintahan Belanda yang sewenang-wenang terhadap rakyat, oleh karena itu saya akan turut serta dalam gerakan perlawanan terhadap Belanda. Hanya ada satu permintaan, yaitu ijinkan anak saya Martha Christina ikut mendampingi saya dalam medan pertempuran. Ia telah memohon dengan sangat agar diperkenankan memanggul senjata saya dan terus mendampingi saya"

Thomas Matulessy kemudian menjawab bahwa mengizinkan Martha Christina berjuang mendampingi ayahnya.

Setelah usai pertemuan itu hasil rapat menunjukkan terpilihnya Kapitan dari Abubu, Paulus Tiahahu, Martha Christina Tiahahu dan Raja Titawaosi yang bernama Hehanusa sebagai pemimpin rakyat wilayah Nusalaut. Demikian juga Anthone Rhebok yang telah dikirim oleh Kapitan Pattimura ke Nusalaut untuk mempersiapkan dan memperkuat strategi perjuangan. Tugas utama Anthone Rhebok adalah mengkoordinasikan pertahanan di Nusalaut. Dalam pertemuan itu mereka juga mengangkat sumpah setia bersama, yang isinya: pertama, tidak akan ada penghianatan dalam perjuangan dan kedua, siapa yang menyeleweng akan dihukum mati ditiang gantungan maka sejak saat itulah, di tahun 1817 saat Martha berusia 17, Martha mulai ikut bergabung dalam gerakan perlawanan Pattimura. Putra-putri dari Nusa Laut juga termotivasi atas semangat yang dikobarkan oleh Kapittan Patimura dan ikut mengangkat senjata untuk mengusir penjajah (Kamajaya, 1981).

Sejarah Bangsa Indonesia mencatat jauh sebelum Marta lahir, daerah Maluku sudah sering dikunjungi Bangsa Eropa, seperti Portugis, Spanyol, Inggris, dan Belanda. Pada awalnya, tujuan kedatangan mereka, khususnya Portugis dan Spanyol berdagang dengan cara membeli apa yang dihasilkan bumi Maluku, seperti cengkeh dan pala untuk mereka bawa dan jual di Eropa. Namun, semakin lama tujuan itu menjadi melenceng dengan adanya keinginan Bangsa Eropa itu untuk menguasai tanah Maluku, karena daerah ini dianggap sangat menguntungkan. Saat Martha lahir hingga terjadi perlawanan Saparua, konstelasi politik di Maluku mengalami perpindahan secara cepat. Belanda yang awalnya berkuasa kemudian digantikan oleh kolonialisme Inggris antara tahun 1810-1816. Demikian juga dengan daerah Nusa Laut, tempat Marta Christina Tiahahu dilahirkan. Belanda mencoba untuk menguasai wilayah ini dengan cara-cara kekerasan. Lewat Organisasi perdagangan VOC (Verenigde Oost Indische), Belanda berhasil mengeruk keuntungan lebih banyak lagi. Keuntungan itu Belanda peroleh dengan menggunakan sistem monopoli barang dagangan, terutama cengkeh dan pala. Sistem monopoli yang dilakukan Belanda sering dilakukan kurang manusiawi. Tujuan monopoli itu adalah untuk menjaga supaya harga rempah-rempah itu tetap stabil. Sistem monopoli yang dilaksanakan itu sering juga dibarengi dengan menggunakan alat senjata, seperti pistol untuk mencapai tujuan yang dimasuk. Praktek yang dilakukan bangsa Belanda pada dasarnya sangat menyakiti hati 
rakyat Maluku. Keadaan inilah yang membuat Martha mempunyai hasrat untuk memberontak dan melawan kezaliman bangsa Belanda.

Hal ini menarik sebab jika kita kaji lebih jauh lagi maka kita akan mendapatkan sebuah pemahaman baru bahwa sistem politik lokal yang tumbuh dan berkembang di pulau Nusalaut dan secara historis maupun kultural, merupakan bagian dari pertumbuhan pemerintahan tradisional diwilayah ini, sehingga secara fisikologi telah membentuk watak dan sikap hidup Martha Christina Tiahahu sebagai seorang perempuan yang terlahir dari darah Maalessi atau kapitan (panglima perang) dari struktur politik pemerintahan tradisional di pulau Nusa Laut. Kedudukan keluarganya sebagai pemangku gelar Maalessi, telah mendorong Ina Martha untuk menegahkkan kebenaran dan menjaga keharmonisan hidup yang telah dilahirkan oleh generasi pendahulunya. Senada ungkapan Zachrias dalam bukunya yang berjudul "Martha Christina Tiahahu" mengatakan bahwa sejarah perjuangan Martha sedikit banyak dipengaruhi oleh ligkungan di mana ia tinggal dan di besarkan (Kamajaya, 1981).

Fakta historis yang terjadi selama pemberontakan berlangsung merupakan determinandeterminan yang akan dianalisa berdasarkan sumbersumber atau bukti-bukti lainnya mengenai pergolakan rakyat Maluku menentang pihak Kompeni Belanda. Determinan-determinan penyebab pemberontakan, dan cleas fages yang menimbulkan pemberontakan rakyat Maluku, secara historis masih terkait langsung dengan kondisi sosial, politik, ekonomi masyarakat di wilayah Maluku, karena hal ini menjadi pijakan kuat penyebab pemberontakan. Sistem politik lokal yang tumbuh dan berkembang sebagai aset berharga bagi tatanan kehidupan masyarakat Nusa Laut.

Dalam penyerbuan Benteng Duurstede Pattimura bersama temantemanya hanya menggunakan potongan-potongan bambu untuk memanjat agar bisa masuk kedalam benteng tersebut. Alhasil Residen van den Berg dan istrinya tewas karena diserbu oleh rakyat yang jumlahnya lebih besar. (Leirissa, 2013) Setelah Benteng Dursteede di saparua jatuh ketangan para, raja Patih dan pemimpinpemimpin rakyat berkumpul dan sepakat mengumumkan apa yang disebut Proklamasi Haria, Proklamasi ini di fungsikan untuk membangun solidaritas dan soliditas antara para pelaku perjuangan. Sehingga proklamasi Haria pada saat itu sangat berfungsi untuk masyarakat, karena memberi dasar bagi revolsui kemerdekaan rakyat serta merupakan pernyataan bahwa revolusi yang terjadi adalah revolusi rakyat yang didukung penuh oleh rakyat (Zachrias, 1984).Alwi, mengklaim bahwa Benteng Duurstede adalah satusatunya benteng kekuasaan Belanda di Indonesia yang dapat di duduki melalui pertempuran oleh pasukan pribumi (Alwi, 2005).

Jatuhnya Benteng Duurstede di Saparua menimbulkan kehebohan dan kemarahan terbesar dikalangan bangsa Belanda. Tiga hari kemudian pimpinan militer di Ambon mengirim sebuah ekspedisi militer yang terdiri atas 300 orang prajurit dengan pimpinan Mayor Beetjes utuk merebut kembali benteng Duurstede(Leirissa, 2013). Pasukan itu di kawal oleh dua pasukan perang yaitu Evertsen dan Nassau. berita tentang gerakan ekspedisi Beetjes sudah di ketahui oleh Pattimura, sehingga Pattimura telah mempersiapkan segala kekuatan untuk menunggu segala kemungkinan yang terjadi. 
Pasukan Pattimura yang berjumlah kurang lebih 1000 orang mengambil tempat di sepanjang pesisir teluk Saparua dalam Benteng Duurstede. Begitu Beetjes mendarat bersama pasukannya langsung di serbu oleh peluru-peluru yang dilancarakan oleh pasukan Pattimura. Hal ini di perkuat oleh pernyataan Van der Kem bahwa Pasukan Pattimura telah menerima serdadu-serdadu Belanda dengan tembakan-tembakan yang seru dan tepat. Sehingga dalam waktu yang singkat pasukan musuh terdesak dan terpaksa mundur dan melarikan diri (VerHuell, 1835). Namun kapal yang di tumpanginya telah hanyut ke laut sehingga dengan mudah pasukan Pattimura untuk menghabisi mereka termasuk Mayor Beetjes pun tewas.

Kemenangan yang gemilang ini menambah semangat juang rakyat Maluku, sehingga perlawanan meluas kedaerah lain seperti Seram, Hitu dan Lain-lain. Selanjutnya Pattimura mengonsentrasikan pasukanya untuk merebut Benteng Zeelandia dipulau Haruku. Pada tanggal 30 mei 1817 jam 14.00 kapitan Selano memberi komando serangan kepada rakyat, sambil berteriak untuk menyerang Benteng Zeelandia. Maka terjadilah tembak menembak antara rakyat dan Belanda. Tembakan rakyat tersebut di bals oleh tembakan meriam yang gencar sehingga rakyat tidak berhasil merebut benteng Zeelandia. Berita kegagalan rakyat di Haruku sampai di Haria dan saat itu Pattimura sangat marah. Hingga pada tanggal 3 juni dan 14 juni pasukan rakyat mendakan serangan terhadap Belanda di Haruku tetapi ternyata pertahanan Benteng terlalu kuat dan untuk di patahkan.

Pada hari-hari selanjutnya dalam perlawanan terhadap Belanda rakyat Nusalaut yang di pimpin oleh kapitan Abub, Paulus Tiahahu dan Martha Christina Tiahahu serta Hehanussa raja Titawaai. Dalam semangat yang kuat pasukan Nusa Laut dibawah pimpinan empat pejuang ini mengadakan serangan terhadap Benteng Beverwijk di Sila-Leinitu. Awal perlawanan, benteng Beverwijk di Nusa Laut dapat direbut rakyat dengan mudahnya. Semua serdadu Belanda semua di bunuh terkeculi seorang kopral Belanda yang bernama Biroe dan dua orang serdadu bangsa Indonesia yang berhasil menyembunyikan diri. Di dalam perjuangan tersebut, Martha Christina selalu terlibat dalam mengobarkan semangat perang .

Zacharias, mengatakan bahwa dalam perjuangan tersebut srikandi Nusalaut, Martha Christina Tiahahu menunjukkan keberaniannya yang luar biasa. Ia telah mengobarkan semangat perjuangan dan menanam rasa permusuhan yang mendalam kepada seluruh rakyat untuk bangkit melawan Belanda. Ia ikut bertempur dengan gagah berani, sehingga seorang penulis Belanda Van De Wall mencatat di dalam bukunya yang berjudul“" De Nederlandsche Oudheiden in de Malukken sebagai berikut (Zachrias, 1984):

"Het Blokhuis Beverwijk herinnert niet alleen aan de Campanie,aan het herstel van het Nederlansche gezag in 1817 maar ook aan den moed, de doodsverachting en de trow van een heldhafting mesje Christina Martha Tiahahu. Artinya Benteng Beverwijk bukan saja merupakan peringatan kepada Kompeni atas berdirinya kembali kekuasaan Belanda dalam tahun 1817, tetapi juga atas keberanian, sifat yang tidak takut mati dan kesetiaan dari seorang gadis pahlawan ialah Christina Martha Tiahahu .

Demikian juga yang ditulis oleh Zachrias bahwa di tengah medan laga yang begitu seru nampak srikandi Nusalaut, Martha Christina Tiahahu yang pantang mundur bercakalele (menari tarian perang) memberi semangat kepada pasukannya untuk menghancurkan musuh (Zachrias, 1984). 
Mengenai hal itu di kemukakan oleh Ver-Huell (1835) dalam catatanya sebagai berikut:

"Dalam suasana pertempuran bukan saja ia telah menolong memikul senjata ayahnya tetapi juga telah ikut serta dengan pemimpin-pemimpin perang mengadakan tarian perang dan telah memperlihatkan kecakpanya kecakapanya, keberanianya dan kewibawaanya.

Kehormatan dan kedudukan Martha Christina Tiahahu berada langsung dalam struktur pemerintahan di atas, sehingga membuat ia sejak awal perjuangan, selalu ikut mengambil bagian pada pront terdepan dan pantang mundur. Dengan rambutnya yang panjang terurai ke belakang serta berikat kepala sehelai kain berang (merah) ciri pemberani dan keperkasaan,ia tetap mendampingi ayahnya dalam setiap pertempuran baik di Pulau Nusa Laut rnaupun di Pulau Saparua. Siang dan malam ia selalu hadir dan ikut dalam mengatur kubu-kubu pertahanan. la bukan saja mengangkat senjata, tetapi juga memberi semangat kepada kaum wanita di negerinegerinya agar ikut membantu kaum pria di setiap medan pertempuran sehingga Belanda kewalahan menghadapi kaum wanita yang ikut berjuang walaupun dengan perlengkapan perang sangat sederhana.

Ratna, mengatakan bahwa putri pemberani itu mampu menyemangati kaum perempuan di Ulath dan Ouw. Martha mengajak agar para perempuan ikut serta mendampingi para pejuang dalam melawan Belanda. Dengan semangat yang tinggi Martha Christina Tiahahu sambil mengencangkan ikatan kain merah dikepalanya dan berteriak " Tanah ini tanah tempat kita dilahirkan, jangan biarkan penjajah merebutnya!" (Indah, 2017). Dalam pertempuran di Ulat dan Ouw tekad Martha untuk menumpas Belanda benar-benar nampak. dengan semangat berapi-api turun kemedan laga. Bahkan ketika senjata api kehabisan mesiu, Martha tidak kehabisan akal untuk terus melawan dengan menggunakan batu untuk menggempur musuh. Pada tanggal 12 November terjadi serangan umum. Serangan musuh terhadap rakyat yang sangat luar biasa. Di tengah-tengah peluru yang berdesing, teriakan perang yang berkumandang serta nyala api yang berkobar dari rumah-rumah yang terbakar, tampak putri Christina Tiahahu dengan rambut terurai, tangan mengenggam lembing dalam keadaan tidak berdaya diangkut keluar dalam sebuah rumah yang terbakar. Dengan jatuhnya kubu pertahanan yang terakhir di Lease terumata antara tanggal 11 november sampai dengan 13 November perjuangan pasukan rakyat mengalami masa-masa yang sulit sebab pemimpin-pemimpin pasukan perjuangan seperti Pattimura, Kapitan Paulus Tiahahu, Martha Christina Tiahahu dan pasukan pemimpin lainya berhasil diamankan oleh pasukan Belanda.

Pada 15 November 1817, para tawanan yang sudah ditangkap diperiksa kembali di atas kapal Eversten, dan ternyata di dalamnya terdapat Martha dan ayahnya, Paulus Tiahahu. Dalam pemeriksaan yang dilakukan, Paulus di jatuhi hukuman mati dan hukuman akan dilakukan di Nusalaut. Martha sempat memohon kepada Buyskes, orang yang memvonis mati, untuk membatalkan hukuman tersebut, tapi permohonan tersebut ditolak. Sedangkan Martha Christina, menurut pengakuan sejarah khususnya yang ditulis oleh Ver Huell (1917) dan Van Der Kemp (1917 : 91) mengatakan bahwa Martha Christina Tiahahu tidak jadi di hukum karena umurnya yang dianggap masih muda tidak dijatuhi hukuman mati. 
Pada 17 November, Paulus Tiahahu dieksekusi hukuman mati di Nusa Laut. Martha pun diizinkan untuk keluar Benteng untuk diasuh dan di didik oleh Guru Sosalissa. Namun, sepeninggal kematian ayahnya, Martha lebih sering mengasingkan diri ke dalam hutan. Karena dianggap pengasingannya berbahaya, bersama 39 orang lainnya, Martha kemudian ditangkap kembali dan diangkut ke dalam kapal eversten untuk dibuang dan di pekerjakan secara paksa di perkebunan kopi yang ada di pulau Jawa. Pada akhir Desember 1817, kapal Eversten yang mengangkut Martha Christina menuju Batavia. Selama di atas kapal Eversten, Ver Huell yang merupakan orang Belanda yang menangani dan memantau kesehatan para tawanan senantiasa berusaha menghibur Martha . Sebab diantara tahanantahanan tersebut yang menarik perhatian Ver Huell adalah sosok Martha Crsitina Tiahahu gadis pahlawan gagah berani yang selalu ikut dalam setiap pertempuran. Kekaguman ini dicatat dalam bukunya (Ver-Huell, 1835):

"Segala sesuatu yang saya dengar dan saksikan tentang dia, bukti jiwa besar dan keberanian seorang pahlawan, kasih terhadap orang tua, bertahan dan berkabung karena kehilangan ayahnya"

Martha tempat tersendiri dan memperlakukannya dengan baik. Namun Martha berbeda dengan orang lain yang dapat dibujuk dengan kenyamanan dan kemewahan. Ia adalah anak Paulus Tiahahu, anak yang di didik dari pembelajaran penindasan yang ada di lingkungannya. Di atas kapal itu, Martha masih memiliki kesadaran bahwa ia akan dijadikan budak di Jawa. Martha pun kemudian, dalam keadaan tidak berdaya melanjutkanaksi pemberontakannya terhadap Belanda dengan aksi mogok makan dan mogok pengobatan. Martha juga menolak berkomunikasi dengan awak kapal. Tiap kali awak kapal mengantar jatah makan, Martha tidak menyentuhnya sama sekali. Ia mogok makan meskipun kondisi fisiknya sangat lemah. Di Kapal Perang Eversten, Christina mogok makan sehingga ia meninggal dan dengan penghormatan militer jasadnya diluncurkan di Laut Banda menjelang pagi hari tanggal 2 Januari 1818.

Demi menghargai jasa dan pengorbanannya, Martha Christina Tiahahu dikukuhkan sebagai Pahlawan Kemerdekaan Nasional oleh Pemerintah Republik Indonesia. Sehingaa setiap tanggal 2 Januari diperingati sebagai hari Martha Christina Tiahahu. Peringatan ini bermaksud untuk mengenang kembali semangat dan daya juang Martha. Pada hari ini semangat juang para pemuda di pupuk melalui teladan Martha Christina Tiahahu. Selain itu, di Ambon tepatnya di Karang Panjang, pada 2 Januari 2008 dalam peringatan Hari Martha Christina Tiahahu yang ke 190 pemerintah daerah Maluku yang disetujui oleh pemerintah repulik Indonesia, mendirikan patung Martha sambil memegang tombak yang terbuat dari perunggu dan menghadap ke Teluk Ambon seakan-akan menyiratkan tekadnya menjaga keutuhan Maluku sebagai daerah yang kaya dan berpotensi tinggi dalam sumber daya alam sebagai bagian dari kekuatan masa depan untuk kesejahteraan masyarakat seutuhnya. Tidak hanya di Ambon, tapi di Desa Abubu juga diletakkan patung yang sama, sambil memandang ke laut banda tempat jazat Ina Martha Christina dibuang (Sem, 2017).

Tidak hanya di Indonesia, dimana Martha Christina banyak digunakan sebagai nama jalan, di area pemukiman Wierden, Belanda, nama Marta Christina juga diabadikan menjadi nama sebuah jalan yang berdampingan dengan Pattimurastraat. Namanya juga dijadikan nama kapal perang Indonesia yaitu KRI Martha Christina Tiahahu. Bahkan nama pahlawan Indonesia 
ini dipakai juga nama gedung Mako Lantamal di IX, Ambon. Sekelompok perempuan Maluku di Jakarta juga telah mendirikan Yayasan Martha Christina Tiahahu, sebuah yayasan sosial bagi masyarakat Maluku dipimpin oleh Djaelani Mietje Saimima. Sementara itu, sejumlah aktivis perempuan dan jurnalis di Ambon menerbitkan majalah Martha Christina, yang terinspirasi oleh pejuang kemerdekaan Maluku muda. Publikasi ini juga melibatkan beberapa pejabat seperti Kepala Kantor Informasi lokal, dan Fenno Tahalele, Kepala Kantor Urusan Sosial.

Dari jejak sejarah perjuangan Martha Christina Tiahahu, kita mendapati jejak sejarah yang luar biasa bagi proses perlawanan kolonialisme di bumi Maluku. Dari uraian di atas, paling tidak, sedikitnya ada beberapa hal penting yang dapat kita pelajari dari figure Martha Christina Tiahahu yang bisa di ajarkan kepada peserta didik dalam proses pembelajaran sejarah. Pertama, Martha Christina Tiahahu pejuang perempuan yang rela mati demi melawan kezaliman dan membela kebenaran. Kedua, Martha Christina Tiahahu adalah sosok pejuang yang mempunyai komitmen yang tinggi terhadap cita-cita perjuangan. Ketiga, Martha Christina Tiahahu adalah salah satu tokoh di dunia yang melakukan perlawanan dengan mogok makan. Dengan prinsip lebih baik mati dari pada di perbudak bangsa penjajah. Keempat, dari perjuangan Martha Christina Tiahahu kita belajar bahwa perjuangan melawan penjajahan tidak hanya di bangun berdasarkan jenis kelamin, agama, suku maupun ras akan tetapi praktek penindasan selalu di jawab dengan bahasa perlawanan.

Pengintegrasian semangat juang dari tokoh Martha Christina Tiahahu bukan untuk mengajarkan siswa bagaimana melakukan perlawanan atau terlibat langsung dalam peperangan dan mengangkat senjata, akan tetapi bagaimana perlawanan itu dimaknai sebagai kritik atas permasalahan sosial ekonomi yang terjadi. Kaitanya dalam dunia pendidikan, khususnya pembelajaran sejarah, peserta didik dapat memaknai semangat juang Martha Christina Tiahahu dalam melakukan perubahan kehidupan sosial ekonomi ke arah yang lebih baik. Bagi masyarakat Maluku, semangat kejuangan Martha Kristina Tiahahu dapat di implementasikan sebagai gerakan pembaharuan pendidikan saat ini lebih khusus melalui pegajaran sejarah agar peserta didik atau generasi muda dapat mengambil nilai juang dari perjuangan tersebut dalam rangka meningkatkan kesadaran sejarah sekaligus menanamkan rasa cinta akan tanah air dan bangsa Indonesia.

\section{Simpulan}

Keberadaan Martha Christina dalam perlawanan Pattimura menunjukkan keragaman perjuangan rakyat Maluku. Perjuangan perlawanan terhadap penjajahan tidak dapat dibedakan berdasar jenis kelamin, agama atau asal wilayah. Kesamaan agama antara pihak penjajah dengan pihak yang melawan juga merupakan sebuah simbol, bahwa bahasa melawan ketertindasan melampaui itu semua. Apabila mempertimbangkan aspek agama, tentunya rakyat Maluku tengah yang Kristen Protestan mustahil melawan belanda. Kenyataan menunjukkan bukti yang berbeda. Sekali lagi, ketertindasan selalu melahirkan bahasa yang sama yaitu perlawanan. Sehingga apa yang dilakukan oleh Martha Christina Tiahahu harus menjadi panutan untuk 
semua masyarakat Indonesia khususnya generasi muda penerus bangsa. Demikian halnya yang pernah diungkapkan oleh Guru besar Unpatti Ambon Prof Mus Huliselan mengatakan, nilai kepahlawanan Martha Christina Tiahahu masih tetap penting sampai saat ini dan bisa menjadi panutan sebab sejarah perjuangan bangsa ini tidak terlepas dari buah karya para tokoh yang telah rela berkorban memperjuangkan hak kemerdekaan di mata dunia. Hal yang paling penting disini adalah sejauh mana kita sebagai generasi muda bisa menjaga komitmen, kemurnian esensi dari semangat kejuangan Martha Christina Tiahahu.

\section{Daftar Rujukan}

Alwi, D. (2005). Sejarah Maluku: Banda Naira, Ternate, Tidore, dan Ambon. Dian Rakyat.

Cribb, R. B., \& Kahin, A. (2012). Kamus Sejarah Indonesia. Komunitas Bambu.

Franco, Z. E., Allison, S. T., Kinsella, E. L., Kohen, A., Langdon, M., \& Zimbardo, P. G. (2018). Heroism research: A review of theories, methods, challenges, and trends. Journal of Humanistic Psychology, 58(4), 382-396.

Galinowicz, A. (2015). Mimicry en hybriditeit in koloniale en postkoloniale literatuur. Een postkoloniale analyse van Christina Martha van Q.M.R. Ver Huell, Aboe Bakar van P.A. Daum, Buiten het gareel van S. Djojopoespito en Tussen Ambon en Amsterdam van H. Keppy. Leiden University.

Humaidi. (2015). Perjuangan Martha Christina Tiahahu (1800-1818). Makalah ini di sampaikan dalam kegiatan diskusi mengenai Martha Christina Tiahahu di Museum Kebangkitan Nasional.

Indah, R. (2017). Martha Christina Tiahahu "Mutiara Dari Nusa Laut yang Cinta Tanah Air." Bee Media Pustaka.

J., J. L. (1984). Putri Karang Di Laut Banda.

J.A, P. (1996). Biaografi Tokoh dan Pahlawan nasional Martha Cristina Tiahahu.

Kamajaya. (1981). Dua Putera-Puteri Maluku Pahlawan Nasional. U.P Indonesia.

Kartodirdjo, S. (1992). Pendekatan ilmu Sosial dalam Metodologi Sejarah. Gramedia Pustaka Utama.

Leirissa. (2013). Pattimura dari Saparua dalam buku "Indonesia Dalam Sejarah."

Marpelina Leni, Akhmad A.M, C. D. (2019). Jejak Patriotisme Dan Perjuangan Martha Christina Tiahahu. Buana Grafika.

Ricklefs, M. C. (2008). Sejarah Indonesia Modern 1200-2008 (p. 31). Penerbit Serambi.

Sem, T. (2017). Martha Christina Tiahahu pejuang dan martir Dalam perang pattimura. Seminar Nasional.

Ver-Huell, Q. M. R. (1835). Herrinneringen van eene Reis naar de Oost-Indien (Vol. 1). 
DIAKRONIKA 20 (2) 2020 ISSN: 1411-1764 (Print) | 2620-9446 (Online)

Wardani, D. (2016). Reenactment Nilai-nilai Kepahlawanan Melalui Pembelajaran Sejarah dengan Menggunakan Metode Histrionik. SUSURGALUR, 4(1).

Wiriaatmadja, R. (2002). Pendidikan Sejarah Indonesia, Perspektif Lokal, Nasional dan Global. Historia Utama Press.

Zachrias, L. J. H. (1984). Martha Christina Tiahahu. Departemen Pendidikan dan Kebudayaan Direktorat Sejarah dan Nilai Tradisional.

Zed, Mestika. (2014). Metode Penelitian Kepustakaan. Yayasan Obor: Jakarta 